\title{
EXPERIENCE OF SURGICAL TRACHEOSTOMY IN COVID-19 HOSPITAL
}

\author{
Saleem Asif Niazi, Yausra Riaz, Shahzad Maqbool, Zafar Ullah Khan, Asjad Sharif, Muhammad Umar Aasim*, Kaswar Sajjad, \\ Shafaq Zaman
}

Pak Emirates Military Hospital/National University of Medical Sciences (NUMS) Rawalpindi Pakistan, *Combined Military Hospital Bahawalpur/National University of Medical Sciences (NUMS) Pakistan

\section{ABSTRACT}

Objective: To share our experience of tracheostomy in COVID-19 positive patients.

Study Design: Prospective observational study.

Place and Duration of Study: Pak-Emirates Military Hospital, Rawalpindi Pakistan, from Apr to Jul 2020.

Methodology: A total of 94 COVID-19 positive cases admitted to the Intensive Care Unit of this hospital, placed on ventilatory support and who ultimately underwent tracheostomy (whether percutaneous or surgical) were included in the study. Patients were included irrespective of any age group or gender.

Results: Out of 94 patients placed on ventilator, tracheostomy was performed only in 17 patients. Male predominance was $13(76 \%)$, with mean age of patients as $55.59 \pm 12.93$ in 12 patients, surgical tracheostomy was performed (70.58\%) whereas in 5 $(29.4 \%)$ cases percutaneous tracheostomy was done. On post-operative follow-up 8 out of 17 (47\%) patients recovered and were successfully decannulated whereas $9(52.9 \%)$ patients could not survive. Tracheostomy was successfully performed as early as 8th day of mechanical ventilator support. Health Care Workers (HCWs) involved were subjected to RT-PCR and remained negative for SARS- CoV-2. There was statistically significant association between the type and indication of tracheostomy, $p=0.002$.

Conclusion: Tracheostomy, in COVID-19 positive patients, being aerosol- generating procedure remains a medical hazard for the HCWs. By following strict safety protocols according to the medical resources available and training of the HCWs, it can be performed with complete safety. It can be done as early as 8th day of ventilator support.

Keywords: COVID-19, Health care workers, Tracheostomy.

How to Cite This Article: Niazi SA, Riaz Y, Maqbool S, Khan ZU, Sharif A, Aasim MU, Sajjad K, Zaman S. Experience of Surgical Tracheostomy in COVID-19 Hospital. Pak Armed Forces Med J 2021; 71(5): 1713-1717. $\quad$ doi: https://doi.org/10.51253/pafmj.v71i5.5148

This is an Open Access article distributed under the terms of the Creative Commons Attribution License (https://creativecommons.org/licenses/by-nc/4.0/), which permits unrestricted use, distribution, and reproduction in any medium, provided the original work is properly cited.

\section{INTRODUCTION}

Severe Acute Respiratory Syndrome Corona Virus 2 (SARS-CoV-2) commonly known as, COVID19 , is a highly infectious \& contagious disease primarily targeting lungs. Since its inception in Wuhan, China in last quarter of 2019, it has swiftly spread across the world. WHO declared COVID-19 as pandemic on $11^{\text {th }}$ March 2020. So far, it has affected more than $16,050,417$ people with fatalities amounting to $6,43,975$ worldwide. With the alarming figures it has become a foremost global health issue. ${ }^{1}$ It has resulted in unprecedented numbers of patients being admitted to Intensive Care Units (ICUs) with additional capacity created in medical facilities globally to meet the overwhelming demand. ${ }^{2}$

Pakistan got its first case diagnosed on 27 Feb 2020 and thereafter the number of cases is on exponential rise. To date more than 2,74,89 cases have been

Correspondence: Dr Saleem Asif Niazi, Associate Professor of ENT, Pak Emirates Military Hospital, Rawalpindi Pakistan

Received: 22 Aug 2020; revision received: 16 Feb 2021; accepted: 17 Feb 2021 diagnosed. While 5842 (2.1\%) patients lost their lives.

The morbidity associated with COVID-19 is acute respiratory distress syndrome (ARDS) \& pneumonia, making tracheostomy, an important element of care, for cases requiring prolonged ventilation. Tracheostomy has conventionally played vital in ventilator weaning, and its role in COVID-19 is now a primary focus. ${ }^{3}$ It is otherwise, one of the most common and frequently performed surgical procedures in ICU. 4 Tracheostomy is preferably performed in operation theatre. However, percutaneous dilatational tracheostomy (PDT) can be performed by the bedside in the ICU, by the surgeon and the intensivist. Initially, in our hospital, PDTs were performed by critical care physicians, but due to shortage of kits in the local market and financial restraints, surgical tracheostomy was opted.

Indications for tracheostomy include long term mechanical ventilation, failure/difficulty to wean off, upper airway obstruction, and airway protection. In ICUs, it is mostly indicated for prolonged mechanical ventilation. ${ }^{4}$ Currently, approximately $10-24 \%$ of COVD-19 positive patients of ICU need mechanical 
ventilator support. However, prolonged endotracheal intubation carries its own morbidity in terms of vocal cord paralysis, glottic and subglottic stenosis, and various infections. In recent years, tracheostomy (percutaneous or surgical) has usually been recommended to decrease these complications. The procedure entails obvious advantages to decrease dead space volume, expedite clearing of tenacious/infected pulmonary secretions and offer patient comfort in the period of weaning off from the mechanical ventilator. ${ }^{5}$

Transmission of the SARS-CoV-2 virus is mostly thought to be through aerosolization or contact with soiled surfaces. Tracheostomy is rated among top most aerosol-generating procedures (AGP), putting health care workers (HCWs) on high risk of getting infected. ${ }^{3}$

Pak Emirates Military Hospital (PEMH) was declared a COVID hospital from 6 April 2020. From the outset, we received and dealt with COVID-19 positive patients. Multiple levels of ICUs and high dependency units (HDU) and special indoor wards were created. Patients were categorised and admitted based on their clinical presentation \& severity of COVID-19 infection.

In our study, we share our experience of surgical tracheostomy in COVID-19 patients; in terms of indications, special precautions, surgical methods evolved and related difficulties faced.

\section{METHODOLOGY}

This was a prospective observational study, conducted at Pak Emirates Military Hospital; from April to July 2020. Approval was sought from the Hospital Ethics Committee (ref no. A/28/68/EC/2020) and attendants of the patients, regarding non disclosure of identity. Patients were included irrespective of any age group or gender. Sampling technique was non probability consecutive technique.

Inclusion criteria: all COVID-19 positive cases admitted to the ICU, placed on ventilator support and who ultimately underwent tracheostomy (whether percutaneous or surgical) were included in the study.

Exclusion criteria: indoor patients in HDU and other wards were not included in the study.

Detailed history about general condition of patient, co-morbids, relevant laboratory indices, number of days of intubation i.e. tracheostomy performed either within two weeks of endotracheal intubation or after two weeks, was obtained. Terminal patients were not subjected to the surgical trauma and were excluded from the study. Tracheostomies were performed in patients with need of prolonged ventilation or having excessive bronchial secretions or in need to be weaned off the ventilator. Special precautionary measures for the HCWs were adapted in surgical as well as percutaneous Tracheostomies.

Double polythene wrap technique (discussed later) was used for surgical tracheostomies to avoid exposure to aerosols generated. HCWs of tracheostomy team were subjected to real time reverse transcription polymerase chain reaction (RT-PCR) test for COVID-19 after every tracheostomy. Post operative care was as per protocol.

Data was collected from ICUs and main operation theatre on a structured proforma. Statistical analysis of all data obtained was done using Statistical Package for Social Sciences (SPSS) version 23. Age, gender and indications of tracheostomy were the major variables of this study pearson chi square test was used. The $p$ value $\leq 0.05$ was considered significant.

\section{RESULTS}

During our study period a total of 94, COVID-19 positive patients were placed on ventilator. Tracheostomy was performed in 17 patients only. Age of patients ranged from 32-77 years with mean age of 55.59 \pm 12.93 years. Male predominance was $13(76 \%)$ out of total 17. Indications for tracheostomy (percutaneous or surgical) were mostly for weaning off from ventilator $11(64.7 \%)$. For removal of airway secretions 4 $(23.52 \%)$; and lastly $2(11.76 \%)$ for prolonged ventilation, as per Table-I.

Table-I: Summary of baseline variables.

\begin{tabular}{|c|c|}
\hline Base line variables & Number of patients (\%) \\
\hline \multicolumn{2}{|l|}{ Age group } \\
\hline 20-40 years & $03(17.6 \%)$ \\
\hline 41-60 years & $08(47.1 \%)$ \\
\hline $61-80$ years & $06(35.3 \%)$ \\
\hline \multicolumn{2}{|l|}{ Gender } \\
\hline Male & $13(76 \%)$ \\
\hline Female & $04(24 \%)$ \\
\hline \multicolumn{2}{|l|}{ Indications of Tracheostomy } \\
\hline Weaning off the ventilator & $11(64 \%)$ \\
\hline Removal of airway secretions & $4(23.52 \%)$ \\
\hline Prolonged ventilation & $2(11.76 \%)$ \\
\hline
\end{tabular}

Surgical tracheostomy was performed in 12 $(70.58 \%)$ whereas in $5(29.4 \%)$ percutaneous tracheostomy was done as shown in Figure. For surgical tracheostomy, $10(58.8 \%)$ patients had indication of weaning off from ventilator, whereas $2(11.8 \%)$ had indication for prolonged ventilation. For percutaneous tracheostomy $1(5.9 \%)$ had indication of weaning off from ventilator and $4(23.5 \%)$ had indication of removal of 


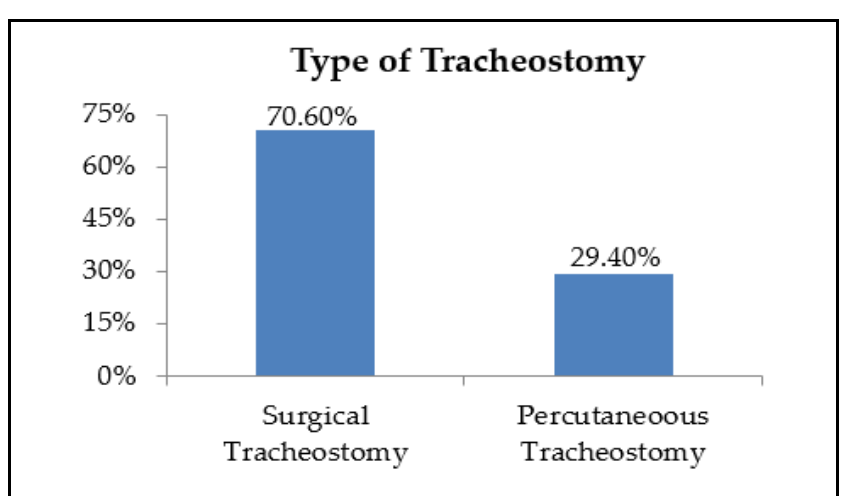

Figure: Percentage of type of tracheostomy.

excessive secretions $p=0.002$ shown in Table-II. Tracheostomy within two weeks of intubation was performed in 10 patients; and in 7 patients after two weeks of endotracheal intubation. On post-operative follow-up, $8(47 \%)$ patients recovered and were successfully decannulated. Whereas, 9 patients $(52.9 \%)$ could not survive. As far as HCWs were are concerned, none were detected positive for SARS-CoV-2.

Table-II: Association of type and indication of tracheostomy.

\begin{tabular}{|c|c|c|c|}
\hline \multirow[b]{2}{*}{$\begin{array}{l}\text { Indication of } \\
\text { tracheostomy }\end{array}$} & \multicolumn{2}{|c|}{ Type of tracheostomy } & \multirow[b]{2}{*}{$\begin{array}{c}p- \\
\text { value }\end{array}$} \\
\hline & $\begin{array}{c}\text { Surgical } \\
\text { tracheostimy }\end{array}$ & $\begin{array}{l}\text { Percutaneoous } \\
\text { tracheostomy }\end{array}$ & \\
\hline $\begin{array}{l}\text { Wean off from } \\
\text { ventilator }\end{array}$ & $10(58.8) \%$ & $1(5.9 \%)$ & \multirow{3}{*}{0.002} \\
\hline $\begin{array}{l}\text { Removal of } \\
\text { excessive } \\
\text { secretions }\end{array}$ & - & $4(23.5 \%)$ & \\
\hline $\begin{array}{l}\text { Prolonged } \\
\text { ventilation }\end{array}$ & $2(11.8 \%)$ & - & \\
\hline
\end{tabular}

\section{DISCUSSION}

SARS CoV-2 or COVID-19 predominantly targets the human respiratory system. People infected with the virus, mostly experience mild to moderate respiratory illness and recover without any special treatment. Older people and those with co-morbids are more prone to developing serious illnesses. The symptoms of COVID-19 become apparent after an incubation period of approximately 5-6 days. In Pakistan, the mortality rate never exceeded $>1.8 \%$.

The most common symptoms at onset of COVID19 illness are fever or chills, cough, shortness of breath or difficulty in breathing, fatigue, malaise, and headache. While other symptoms include loss of taste or smell, sore throat, diarrhoea, nausea and vomiting. Computerized tomographic findings in chest are bilateral ground glass opacities (GGO) and enlarged blood vessels. Clinical features like, RNAemia, acute respiratory distress syndrome, acute cardiac injury, and incidence of GGO lead to the death of infected patients. ${ }^{6}$

Countries across the globe continue to struggle with escalating numbers of infected patients. The strategic priorities are aimed to limit human-to-human transmission by adopting measures like social distancing, wearing face masks, creating public awareness, case investigation and contact tracing; including prevention of cross infections among vulnerable HCWs. ${ }^{7}$

Tracheostomy is rated in the top most aerosol generating procedure (AGP) but its benefits to the patient over emphasize the risk it holds for the HCWs. The pronounced benefits of tracheostomy include the ability to wean sedation and to facilitate gradual reduction in ventilator support in intubated patients. It participates in rehabilitation, reduces dead space, facilitates bronchial toilet, and potentially reduces longterm complications of endotracheal intubation such as vocal cord granuloma formation, subglottic stenosis and scarring. ${ }^{8}$ Our major indication for tracheostomy was weaning off the ventilator. While a few, were done for excessive bronchial secretions. In our hospital, we had the advantage that all admitted cases were confirmed patients of COVID-19. We were clear in our heads about the potential threats it can pose and the protocols we had to adopt before embarking on the surgical venture.

The complications and specific risks of tracheostomy are well recognised in COVID-19 patients. Tracheostomy is primarily performed in critically ill subjects with high viral loads leading to more chances of cross infection. Its management is therefore, of paramount importance to prevent cross-contamination between patients and HCWs.

The risk of transmission may be increased by aerosolization of particles. Tracheostomy during this pandemic has helped to reduce the impact of COVID19; however, controversy exists about the timing of tracheostomy. ${ }^{9}$ In general, decision to go for tracheostomy is made on a case-to-case basis. ${ }^{10,11}$ However, in non-COVID-19 patients an early tracheostomy is advocated, especially in patients with traumatic brain injury and other trauma-related injuries.

Bearing the benefits of tracheostomy in mind, it has to be performed. Different viewpoints exist, some advocate an early tracheostomy; while others suggest, to wait for the patient to become COVID negative.12-16 Elkbuli et al, in a study recommended to postpone elective tracheostomy in COVID-19 positive patients until they tested negative, if possible. ${ }^{10}$ Scientists like 
Harrison et al, Wax et al and Chen et al, in their scholarly articles endorsed that if resources allow, all tracheostomy patients should be tested for COVID-19 within 48 hours prior to surgery. ${ }^{12-16}$ However, Noah et al, from America concluded that tracheostomy should be avoided in patients with respiratory instability. ${ }^{17}$

Prior education and rehearsal of HCWs before donning will ensure that all involved parties are adequately informed and work smoothly. ${ }^{18,19}$ Factors like exposure to endobronchial secretions, combined with the presumed peak viral load in early illness confer to the consensus for later tracheostomy in COVID-19.19-21

Initially with limited experience, we were reluctant to perform early tracheostomy, but as the time passed we refashioned our indications for the surgery. COVID positive patients with clear signs of improvement had to be weaned off the ventilator. Therefore, we started performing tracheostomy as early as on $8^{\text {th }}$ day of assisted ventilation, against the guidelines, and did not wait for a negative test result. Thus, we agreed with McGrath et al, and suggest that standard decision making may be adopted for the COVID-19 pandemic, taking into account a range of considerations including potential risks and benefits for the patient and risks posed to HCWs and available health-care resources. ${ }^{22}$

Patient selection for tracheostomy was another important consideration. COVID-19 positive patients on ventilator, with good prognosis and obvious clinical and laboratory signs of improvement were selected. Our well thought out selection criteria led to zero mortality.

As far as the donning for the procedure was concerned, all researchers agreed to the standard protocol of wearing personal protective equipment (PPE) augmented by surgical and polythene gowns, double gloves, goggles and face shield. However, visibility \& fogging were disturbing but were managed.

The surgical procedure of tracheostomy was delineated and followed as per standard protocol.22 A cuffed non-fenestrated tracheostomy tube was used to avoid aerosolizing the virus. Largest tracheostomy tube appropriate for the patient was recommended. Intravenous glycopyrrolate $(0.4 \mathrm{mg})$ was used to reduce airway secretions. Lidocaine $2 \%$ with 1:100,000 epinephrine minimized bleeding and need for frequent suctioning. Electrocautery was avoided; however if available smoke evacuator cautery is recommended. Vigilance was practised not to pierce the cuff of the endotracheal tube (ETT) during tracheotomy. Anesthesiologist was requested to cease ventilation whilst win- dow in the trachea was made and swift and accurate placement of tube was done. Prompt adequate inflation of the cuff to minimize leakage was the next step. Placement of the tube was confirmed with end tidal $\mathrm{CO}_{2}$. Tube was secured in position. Stoma covered with surgical gauze and minimal tracheal suctioning done. Heat and moisture exchanger (HME) was placed on the tracheostomy to reduce shedding of the virus should the anesthetic tubing be disconnected.

We used an improvised double polythene wrap technique on the patients to further reduce the risk of aerosol transmission. The patient was transported to main operation theatre wrapped in a polythene sheet with ETT in situ. As this sheet was to be incised, to gain surgical access to the neck so another polythene sheet was spread over the first one and the procedure was performed under the sheet. The surgical instruments used were left under the polythene sheet and were only removed once a close- circuit was established. We recommend special operating rooms, to be established in the ICUs premises to add to the safety of the HCWs involved in the transportation of the patients.

Airborne precautions should be meticulously followed by all surgical team members/HCWs. ${ }^{12-18}$ The operating room team should be reduced to only essential staff. We had a "designated tracheostomy team". One surgeon, one anaesthesiologist, and two surgical/ anesthesia assistants; constituted our team in the hospital. Procedure was performed by the most experienced staff available, to maximize safety and efficiency, as per guidelines. ${ }^{13,16,17,23}$ Routine follow up COVID tests (RT-PCR) were carried out by all team members. Fortunately, no HCW of our team was exposed/ affected by the virus.

Best possible post-operative care of tracheostomy was followed. Bed head information signs were displayed and significance of close circuit ventilation was emphasized. Tracheostomy tube cuff was kept inflated to keep airway protected to avoid aspiration. Closed in-line suction with minimal suctioning was used, to keep airway patent. Routine change of tracheostomy tube was discouraged. ${ }^{23}$

This study was conducted in the largest COVID hospital of the country. The purpose of this study was to instigate the global \& national ENT surgeons \& HCWs to accelerate the research and development process for surgical tracheostomy in the wake of corona pandemic. Caring for those affected while concurrently making safety of HCWs impeccable. We further urge 
that the double polythene wrap technique for tracheostomy should be evaluated in other hospitals.

\section{CONCLUSION}

Tracheostomy in COVID-19 positive patients is an AGP and can be a medical hazard for the HCWs. However, following strict safety protocols according to the medical resources available and training of the HCWs, it can be conducted with complete safety. It can be performed as early as 8th day of ventilator support.

\section{Conflict of Interest: None.}

\section{Authors' Contribution}

SAN: Conceptualization of study design, drafting and revision, YR: Literature search, data acquisition, write up.

SM: Data interpretation, write up, ZUK: Literature search, data collection and analysis, AS: Data analysis, write up

MUA: Data acquisition and analysis, KS: Literature search, data analysis, SZ: Data acquisition and analysis.

\section{REFERENCES}

1. Lai CC, Shih TP, Ko WC, Tang HJ, Hsueh PR. Severe acute respiratory syndrome coronavirus 2 (SARS-CoV-2) and coron-avirus disease-2019 (COVID-19): The epidemic and the challen-ges. Int J Antimicrob Agents 2020; 55(3): 105924.

2. Phua J, Weng L, Ling L, Egi M, Lim CM, Divatia JV,et al. Inten-sive care management of coronavirus disease 2019 (COVID-19): challenges and recommendations. Lancet Respir Med 2019; 8(5): 506-517.

3. David AP, Russell MD, El-Sayed IH, Russell MS. Tracheostomy guidelines developed at a large academic medical center during the COVID-19 pandemic. Head Neck 2020; 42(6): 1291-1296.

4. El-Anwar MW, Nofal AA, Shawadfy MA, Maaty A, Khazbak AO. Tracheostomy in the intensive care unit: a university hospital in a developing country study. Int Arch Otorhinolaryngol 2017; 21(1): 3337.

5. Boran OF, Bilal B, Bilal N, Oksuz H, Boran M, Yazar FM. Comparison of the efficacy of surgical tracheostomy and percutaneous dilatational tracheostomy with flexible lightwand and ultrasonography in geriatric intensive care patients. Geriatr Gerontol Int 2020; 20(3): 201-205.

6. Rothan HA, Byrareddy SN. The epidemiology and pathogenesis of coronavirus disease (COVID-19) outbreak. J Autoim 2020; 109(1): 102433.

7. Tay JK, Khoo ML, Loh WS. Surgical considerations for tracheostomy during the COVID-19 pandemic: lessons learned from the severe acute respiratory syndrome outbreak. JAMA Otolaryngol Head Neck Surg. 2020; 146(6): 517-518.

8. Shinn JR, Kimura KS, Campbell BR, Lowery AS, Wootten CT, Garrett CG, et al. Incidence and outcomes of acute laryngeal injury after prolonged mechanical ventilation. Crit Care Med 2019; 47(12): 1699_ 1706.

9. Andriolo BN, Andriolo RB, Saconato H, Atallah AN, Valente O. Early versus late tracheostomy for critically ill patients. Cochrane Database Syst Rev 2015; 1(1): CD007271.
10. Elkbuli A, Narvel RI, Spano PJ, Polcz V, Casin A, Hai S, et al. Early versus late tracheostomy: is there an outcome difference?. Am Surg 2019; 85(1): 370-75.

11. Wang R, Pan C, Wang X, Xu F, Jiang S, Li M. The impact of tracheotomy timing in critically ill patients undergoing mechanical ventilation: A meta-analysis of randomized controlled clinical trials with trial sequential analysis. Heart Lung 2019; 48(1): 46-54.

12. COVID-19 Resources for Anesthesiologists. American Society of Anesthesiologists. 2020, [Internet] Available at: https://www.asahq. org/about-asa/governance-and-committees/asa-committees/ committee-on-occupational-health/coronavirus (Accessed on September 11, 2020.)

13. Brewster DJ, Chrimes NC, Do TBT, Fraser K, Groombridge CJ, Higgs A, et al. Consensus statement: safe airway society princi-ples of airway management and tracheal intubation specific to the COVID19 adult patient group. Med J Aust 2020; 212(10): 472-481.

14. Laura Harrison JR, Winter S. Guidance for Surgical Tracheostomy and Tracheostomy Tube Change during the COVID-19Pandemic. ENT UK. 2020, [Internet] Available at: https://www.entuk.org/ tracheostomy-guidance-during-covid-19-pandemic (Accessed on September 11, 2020.)

15. Wax RS, Christian MD. Practical recommendations for critical care and anesthesiology teams caring for novel coronavirus (2019-nCoV) patients. Can J Anesth 2020; 67(2): 568-576.

16. Chen X, Liu Y, Gong Y, Guo X, Zuo M, Li J, et al. Perioperative management of patients infected with the novel corona virus: Recommendation from the joint task force of the Chinese Society of Anesthesiology and the Chinese Association of Anesthesio-logists. Anesthesiol 2020: 132(6): 1307-1316

17. Anaesthesiologists. Coronavirus-Guidance for Anaesthesia and Perioperative Care Providers 2020, [Internet] Available at: https:// www.wfsahqorg/latest-news/latestnews/943-coronavirus-stayingsafe (Accessed on September 15, 2020.)

18. Kong D. Infographic for Principles of Airway Management in COVID-19. 2020, [Internet] Available at: https://www.aic. cuhk.edu.hk/covid19/. (Accessed on September 15, 2020.)

19. Parker NP, Schiff BA, Fritz MA, Rapoport SK, Schild S, Altman KW, et al. Tracheotomy recommendations during the COVID-19 pandemic. Am Acad Otolaryngol-Head Neck Surg. 2020, [Internet] Available from https://www.entnet.org/content/ tracheotomyrecommendations-during-covid-19-pandemic (Accessed on September 20, 2020.)

20. Takhar A, Walker A, Tricklebank S, Wyncoll D, Hart N, Jacob T, et al. Recommendation of a practical guidelinefor safe tracheostomy. Eur Arch Otorhinolaryngol [Internet] Available from https://doi.org/ 10.1007/s0040 5-020-05993 -x. (Accessed on April 21, 2020)

21. Sommer DD, Engels PT, USAF CEKW, Corsten M, Tewfik MA, Fung $\mathrm{K}$, et al. Recommendations from the CSO-HNS taskforce on performance of tracheotomy during the COVID-19 pandemic. J Otolaryngol 2020; 49(1): 23-28.

22. McGrath BA, Brenner MJ, Warrillow SJ, Pandian V, Arora A Cameron TS, et al. Tracheostomy in the COVID-19 era: Global and multidisciplinary guidance. Lancet Respir Med 2020; 8(7): 717-725.

23. Rovira A, Dawson D, Walker A, Tornari C, Dinham A, Foden N, et al. Tracheostomy care and decannulation during the COVID-19 pandemic. A multidisciplinary clinical practice guideline. Eur Arch Otorhinolaryngol 2020; 1(1): 1-9. 